\title{
Endoscopic removal of two duodenal stents that had migrated into the colon, using the invagination method
}

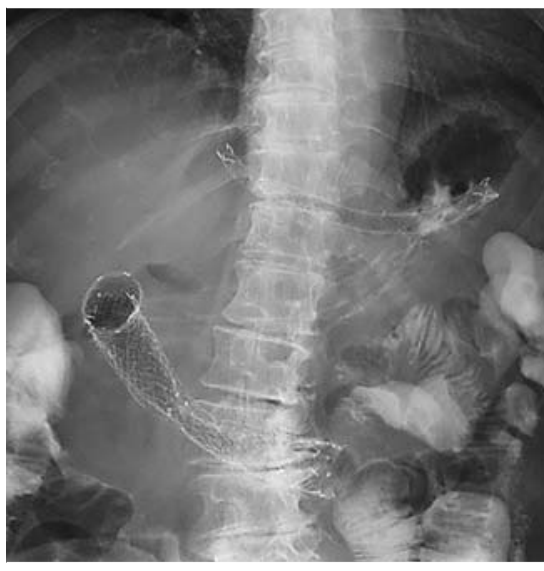

- Fig. 1 Stent placement to treat malignant duodenal obstruction. A partially covered duodenal stent was deployed as a second stent due to tumor ingrowth into an uncovered duodenal stent.

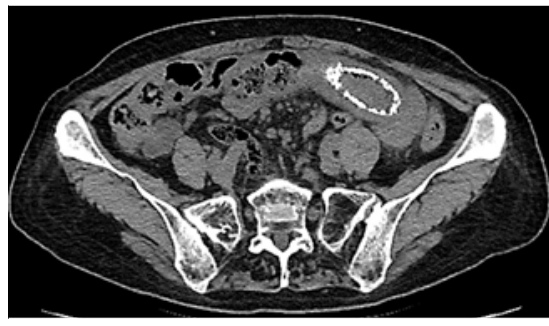

- Fig. 2 Computed tomography revealed that the two duodenal stents had migrated into the colon.

A 77-year-old woman with advanced pancreatic cancer presented with combined biliary and duodenal malignant obstruction. An uncovered self-expandable metal stent (SEMS) (Nexent Duodenal/Pyloric stent, $22 \mathrm{~mm} \times 12 \mathrm{~cm}$; Next Biomedical, Korea) and a partially covered SEMS (Niti-S ComVi stent, $20 \mathrm{~mm} \times 12 \mathrm{~cm}$; Century Medical, Korea) were deployed for the duodenal obstruction ( $\triangleright$ Fig. 1). After three cycles of chemotherapy, the two duodenal SEMSs had migrated to the

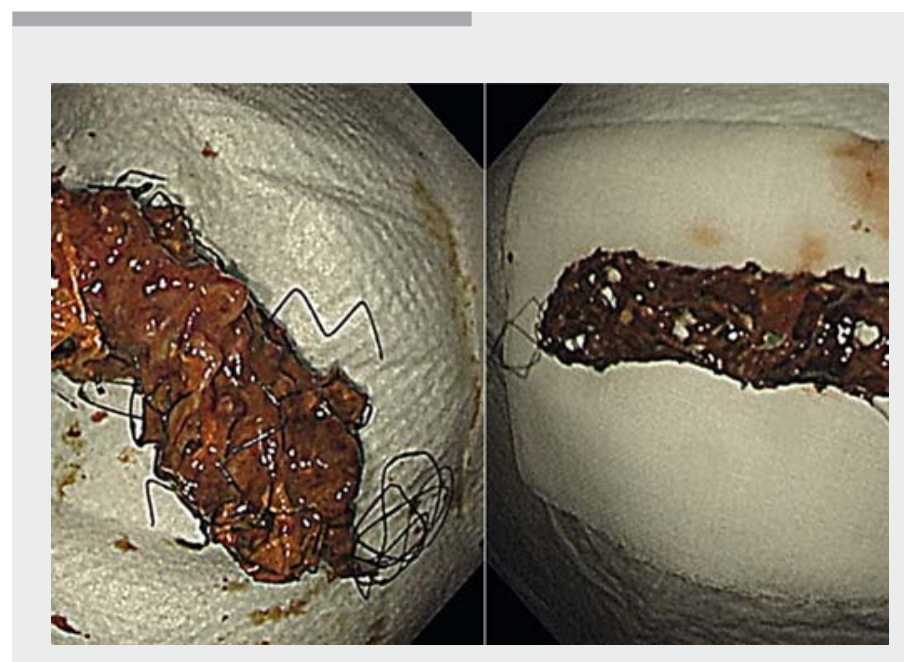

Video 1 Endoscopic removal of two duodenal stents that had migrated into the colon, using the invagination method.

transverse colon ( $>$ Fig. 2 ). We decided to remove the SEMSs to avoid perforation. A short-type single-balloon enteroscope (SIF-H290S; Olympus Medical, Japan) was inserted with the overtube ( $\vee$ Video 1). The SEMSs were identified at the bending part of the colon. We first tried to grasp the distal end with a rattooth forceps, but the SEMSs were tightly embedded in the wall. Therefore, the enteroscope was inserted across the SEMSs and the proximal end of the partially covered SEMS was grasped by the forceps and removed using the invagination method. The SEMSs and the enteroscope were pulled into the overtube so as not to injure the intestinal wall. Both SEMSs were successfully removed without any complications (> Fig. 3, > Fig. 4, > Fig.5; - Video 1).

Several methods have been reported for removal of migrated enteral SEMSs [14]. Most of these techniques are quite difficult when the distal end is located at the bending part of the colon. The invagination method has been reported to facilitate removal of an embedded biliary SEMS [5]. With this method, the proximal end of the SEMS is grasped with forceps and the SEMS removed by pulling it inside itself. This method could be useful when it is difficult to remove a SEMS from the distal end. It is important to lessen the risk of perforation by advancing the overtube near the SEMS, pulling the enteroscope and the SEMS into the overtube, and gradually, little by little, detaching the SEMS from the intestinal wall.

Endoscopy_UCTN_Code_CPL_1AI_2AD

\section{Competing interests}

The authors declare that they have no conflict of interest. 


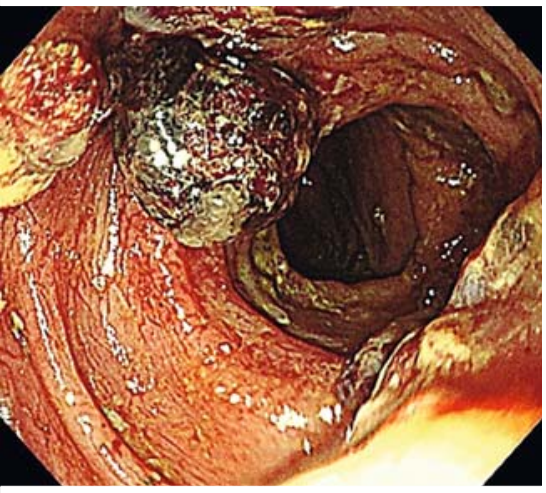

- Fig.3 Colonoscopic view just after stent removal.

The authors

Takashi Sasaki ${ }^{1}$, Tsuyoshi Takeda ${ }^{1}$, Chihiro Yasue $^{2}$, Junki Tokura², Daisuke Ide², Shoichi Saito $^{2}$, Naoki Sasahira ${ }^{1}$

1 Department of Hepato-biliary Pancreatic Medicine, Cancer Institute Hospital of Japanese Foundation for Cancer Research, Tokyo, Japan

2 Department of Lower Gastrointestinal Medicine, Cancer Institute Hospital of Japanese Foundation for Cancer Research, Tokyo, Japan

\section{Corresponding author}

\section{Takashi Sasaki, MD, PhD}

Department of Hepato-biliary Pancreatic Medicine, Cancer Institute Hospital of Japanese Foundation for Cancer Research, 3-8-31, Ariake, Koto, Tokyo 135-8550, Japan Fax: +81-3-3520-0141

sasakit-tky@umin.ac.jp

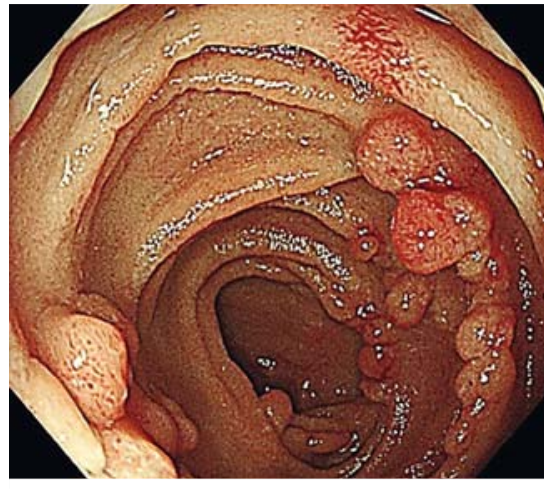

- Fig. 4 Endoscopic view of duodenum where the duodenal stents were previously placed.

\section{References}

[1] Yang DH, Seo M, Lee HJ et al. Stent-in-stent technique and endoscopic resection of granulation tissue to remove a migrated duodenal stent embedded in the colon. Endoscopy 2014; 46: E159-E160

[2] Gutierrez JP, Wilcox CM, Mönkemüller K. Endoscopic removal of a migrated duodenal stent into the ileum using double-balloon enteroscopy. Gastrointest Endosc 2015; 81 : 1033

[3] Zimmer V. 'Knitting-through-the-mesh': novel single-channel troubleshooter technique for dilation-assisted transstricture retrieval of a migrated gastroduodenal stent. Dig Endosc 2018; 30: 265-266

[4] Hori Y, Hayashi K, Sobajima Y et al. Successful peroral endoscopic removal of migrated metal stent. Endoscopy 2019; 51: E339E340

[5] Nakai Y, Isayama H, Kawakubo K et al. Endoscopic removal of a biliary covered metallic stent with the invagination method. Endoscopy 2011; 43 (Suppl. 02): E30-E31

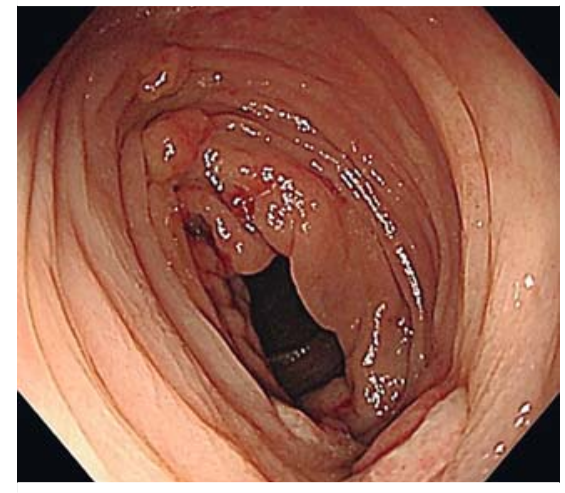

- Fig. 5 Colonoscopic view 1 week after stent removal.

Bibliography

Endoscopy 2021; 53: E209-E210

DOI 10.1055/a-1244-9219

ISSN 0013-726X

published online 11.9.2020

(c) 2020. Thieme. All rights reserved.

Georg Thieme Verlag KG, Rüdigerstraße 14,

70469 Stuttgart, Germany

\section{ENDOSCOPY E-VIDEOS}

https://eref.thieme.de/e-videos

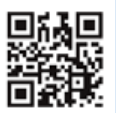

Endoscopy E-Videos is a free access online section, reporting on interesting cases and new

techniques in gastroenterological endoscopy. All papers include a high quality video and all contributions are freely accessible online.

This section has its own submission website at

https://mc.manuscriptcentral.com/e-videos 